Revista de Dialectología y Tradiciones Populares, vol. LXX, n. ${ }^{\circ}$ 2, pp. 307-314, julio-diciembre 2015,

ISSN: 0034-7981, eISSN: 1988-8457,

doi: $10.3989 /$ rdtp.2015.02.001.05

\title{
Externalización fronteriza en el Mediterráneo Occidental: movilidades, violencias y políticas de compasión
}

\author{
Border Externalization in the Western Mediterranean: \\ Mobilities, Violence and the Politics of Compassion
}

\author{
Mercedes G. Jiménez-Álvarez \\ Universidad del Algarve, Portugal \\ Universidad Abdelmalek Essadi, Marruecos
}

\section{RESUMEN}

Basándose en un trabajo de campo de larga duración en Tánger y la frontera entre España y Marruecos, este artículo aborda el efecto de la externalización de la frontera en Marruecos, con un énfasis especial en la experiencia de los niños y jóvenes que atraviesan fronteras en sus proyectos migratorios. A partir del Programa de La Haya de 2004, la deslocalización del control fronterizo empieza a estar presente en la política europea mediante la integración progresiva de terceros países en las tareas de control. Para analizar todos estos procesos, el artículo nos traslada a Bujalef, un barrio "de espera" de la periferia de Tánger — conceptualizado como "penúltima fronteran- - donde tuvo lugar un violento desalojo de inmigrantes subsaharianos en julio de 2015. En este contexto, la autora expone las tres lógicas de gobierno del control fronterizo: la violencia cotidiana — expresada en la falta de seguridad jurídica y la represión-, la movilidad aleatoria - una respuesta lógica al control externalizado-, y la compasión -imbricada en la estructura de la acción humanitaria. El trabajo refuerza la idea de que el respeto a los derechos humanos no es una idea que corra paralela a deslocalización fronteriza.

Palabras clave: Externalización fronteriza; Migración; Marruecos; Derechos Humanos; Políticas de compasión; Violencia cotidiana.

\section{SUMMARY}

Based on a long-term fieldwork in Tangier and the Spanish-Moroccan border, this paper deals with the outsourcing of the Moroccan border, with an emphasis on the experience of the children and youngsters crossing borders in their respective migratory itineraries. After the 2004 The Hague Programme, the delocalization of border control started to be present in European migratory policies though the progressive integration of third countries in control tasks. To analyze the impacts of these policies, the papers brings the reader to Bujalef, a "waiting" suburb in the periphery of Tangier 
—understood as the "Second-to-last border" - where a violent eviction of Sub-Saharan immigrants took place in July of 2015. In this context, the author exposes the three main control policies at work: everyday violence - expressed in the lack of judicial security and in repression-; random mobility - a logical response to outsourcing border control model—; and compassion —intrinsic to the structure of humanitarian action. This paper reinforces the idea that respect for Human Rights does not fit well with border delocalization.

Key words: Border Externalization; Migration; Morocco; Human Rights; Compassion Policies; Everyday Violence.

\section{BUJALEF, PENÚLTIMA FRONTERA}

Finalmente llevaron a cabo la operación de desalojo anunciada. Era el duodécimo día del mes ramadán, principios del mes de julio de 2015. El Ministro del Interior marroquí había lanzado un ultimátum tras los últimos altercados racistas en el barrio y exigía desalojar todos los pisos ocupados antes de 24 horas. En el comunicado declaraba que se recurriría a la fuerza en caso que fuera necesario y que el respeto a la propiedad privada estaba garantizado por la ley. Y a la fuerza recurrió. Unos 2.000 policías y miembros de las Fuerzas Auxiliares se desplegaron por el barrio de Al Irfane II, en Bujalef, a las afueras de Tánger. En los últimos años, este barrio se había convertido en una "pequeña Dakar", un territorio fronterizo de "espera" inserto en las lógicas de movilidad de los extranjeros procedentes principalmente del África del Oes$\mathrm{te}^{24}$, mayoritariamente de Senegal, Camerún, Mali, Nigeria y Guinea Conakry.

Desde hace más de 20 años Marruecos viene siendo país de tránsito de migrantes hacia Europa, muchos de ellos posibles merecedores del estatuto de refugiado. No sólo procedentes de los países de África del Oeste o de la República Democrática de Congo, Congo y República Centroafricana, en África Central, también familias sirias en los últimos tres años han cruzado Marruecos para poder alcanzar las ciudades de Ceuta y Melilla y cruzar a la Península. Tánger es una de las últimas escalas en estas rutas de movilidad, pero también hay otros asentamientos o "espacios de espera" en la zona más oriental, en torno a Melilla y la frontera con Ujda, cerca de Argelia. En las ciudades más importantes del país como Fez, Casablanca o Rabat también se agrupan comunidades de estos países.

Según el Ministerio del Interior, sería desalojado todo aquel que no contara con un documento para la residencia legal y pagara el alquiler de su casa. Sin embargo, también desalojaron a algunos de los que pagaban su vivienda y contaban con residencia legal.

Durante el desalojo, unas 300 personas fueron detenidas y deportadas en autobuses a otras ciudades de Marruecos. Fueron alejados de la ciudad y llevados a improvisados "centros de detención" fuera de toda legalidad, la mayor parte de personas terminaron huyendo ante la amenaza de una expulsión del país.

Días después la policía continuó sacando a la fuerza a los que no habían huido del barrio. Se obviaba así el procedimiento legal que sólo permitía la intervención de la policía

\footnotetext{
${ }^{24}$ Nos referimos a los países que forma parte del espacio CEDEAO, Communauté Economique pour le Développement des États d'Afrique d'Ouest. La CEDEAO permite desde 1975 la circulación libre entre 15 de los países de esta región con el sólo requisito de contar con un documento de identificación y sin la obligatoriedad de un visado.
} 
tras la orden de un juez que ordenara el desalojo. En esa persecución hubo una víctima. Un chico de Costa de Marfil murió en el hospital tras caer al vacío desde un segundo piso. No le atendieron durante las dos horas que estuvo en el hospital hasta su muerte. Sus compañeros, llevados por la indignación, grabaron videos que difundieron para exigir justicia y denunciar esta gravísima vulneración de la atención médica.

Otro grupo de unas 300 personas se refugió en un bosque cercano y allí permanecieron durante semanas en unas condiciones muy precarias esperando un momento propicio para cruzar el Estrecho de Gibraltar o entrar en Ceuta.

Finalmente, otro grupo de 150 personas logró refugiarse durante unos días en la Catedral católica de la ciudad, situada en el centro de Tánger. Durante días denunciaron la situación de precariedad en la que se encontraban tras el desalojo. Le preguntaban al grupo de africanos allí instalado: "Qué necesitáis?" y al unísono, la demanda era la misma: "Necesitamos que nos abran la frontera, ${ }^{25}$. Y en la memoria de muchos estaban las imágenes retransmitidas por la televisión y las redes sociales en verano de 2014, cuando durante el 13 y 14 de agosto esas fronteras insalvables se abrieron, la vigilancia en las costas marroquíes cedió y permitieron que más de 1.200 personas fueran socorridas por Salvamento Marítimo al cruzar el mar en pequeñas embarcaciones de plástico. La Cruz Roja atendió en Tarifa a unas 1.200 personas llegadas en 48 horas. Algunos fueron enviados a Centros de Internamiento para ser expulsados y otros, tras incoarles un expediente de expulsión, fueron recibidos por organizaciones no gubernamentales que durante unos meses se ocuparon de su manutención. "Pero... ¿Nos quieren o no nos quieren? (...) No entiendo a estos europeos. Pagan a Marruecos para que nos maltrate (...) y cuando por fin conseguimos cruzar la frontera, nos quieren expulsar pero no pueden y podemos quedarnos si aceptamos un trabajo y ser explotados", comentaba un compañero camerunés una vez ya en España ${ }^{26}$.

Violencia, compasión, movilidad. A través de estas tres ideas se desgranan en este texto las lógicas en el gobierno del control fronterizo en Marruecos, extensibles a todo el Sur del Mediterráneo. Comenzaremos reflexionando en torno a las violencias estructurales y cotidianas en el tránsito hacia Europa que encierran en los procesos de externalización; continuaremos deteniéndonos en las movilidades que sostienen las estrategias de supervivencia y contestación a estas violencias y finalizaremos con una reflexión sobre las políticas de compasión vehiculadas por la cooperación internacional y que cristalizan en un modo de control de estas movilidades.

\section{VIOLENCIAS}

Cuando en 1993 Marruecos ratificó la Convención internacional sobre la Protección de los Derechos de Trabajadores Migrantes y sus Familias, no imaginó que 20 años después este iba a ser el marco jurídico en el que se apoyaran diversas asociaciones marroquíes para denunciar la falta de seguridad jurídica y la vulneración de los derechos de los migrantes que se daban en el paîs ${ }^{27}$. La ratificación de esta Con-

\footnotetext{
${ }^{25}$ Entrevista a A. T. 5/7/2015

26 Entrevista a G. B. 18/1/2015.

${ }^{27}$ Específicamente nos referimos a las Observaciones Finales del Comité para la Protección de los Derechos de los Trabajadores Migrantes y sus Familias de 18 de septiembre de 2013. http:/ /www.gadem-asso.org/IMG/pdf/CCMW-C-MAR-CO-1.pdf
} 
vención tenía más que ver con la protección de la diáspora marroquí en Europa y América que con la protección de los extranjeros en Marruecos, pero terminó siendo el fundamento del varapalo de Naciones Unidas a estas prácticas y el punto de partida de una nueva política migratoria ${ }^{28}$ auspiciada principalmente por el rey Mohamed VI en el marco de las reformas de la Primavera Árabe en Marruecos.

Marruecos juega un papel fundamental en la externalización de las fronteras europeas junto con el resto de países del Norte de África. A partir del Programa de La Haya (2004), la deslocalización del control empieza a estar presente en la política europea mediante la involucración progresiva de terceros países en tareas de control. La Política Europea de Vecindad (PEV), el Estatuto Avanzado concedido a Marruecos en 2008 y a Túnez en 2014 y finalmente los Acuerdos de Movilidad (Marruecos en 2013 y Túnez en 2014), son los marcos privilegiados en los que la UE ha concretado este proceso. Uno de los objetivos centrales del Acuerdo de Movilidad ratificado en junio del 2013 entre la Unión Europea y Marruecos es firmar un acuerdo de readmisión (similar al ratificado por Turquía) para devolver a los extranjeros que han accedido a la UE a través de Marruecos. Sin embargo, hasta el momento Marruecos se ha negado a aceptar este polémico acuerdo. Hasta ahora consiente la readmisión de sus nacionales, por acuerdos bilaterales con diferentes países y a los extranjeros que intentan cruzar a Ceuta y Melilla. Los medios de comunicación vienen fijando su atención en estas devoluciones "en caliente" en los perímetros fronterizos de Ceuta y Melilla, pero tras la valla física existe un entramado político, jurídico, tecnológico e ideológico (Jiménez-Álvarez, 2014) que sostiene el proceso de externalización de la frontera europea al Sur del Mediterráneo.

En Marruecos, las formas de violencia de la externalización fronteriza se concretan en la falta de seguridad jurídica y en la represión. Efectivamente, en la aplicación de la Ley de Extranjería (2003) no están claros los procedimientos de expulsión y detención y la posibilidad de recurrirlos. No existe el derecho a la tutela judicial efectiva ni mecanismos ordinarios de justicia gratuita. La ausencia de procedimientos y una impunidad por parte de las instituciones del estado, especialmente en los procesos de detención y expulsión del país, tanto con migrantes como con potenciales demandantes de asilo, viene a ser la norma más común. En el recién concluido proceso de regularización de extranjeros —que se expone como botón de muestra de la nueva política migratoria post "Primavera Árabe" y que muchos señalan de exitoso al haber regularizado 19.000 solicitudes de las 28.000 presentadas —, también ha habido una ausencia de rigor administrativo en los procedimientos. Determinadas cuestiones como la renovación de la residencia, quedan al arbitrio de las decisiones políticas, faltos de seguridad jurídica.

La represión de las fuerzas del orden y la muerte de los migrantes por esta represión es otra cuestión largamente denuncia por organismos internacionales de derechos humanos. En 2005, trece personas murieron en las fronteras de Ceuta y Melilla, en lo que fue denominada "la Crisis de las Vallas", por tiros de la Gendarmería ma-

${ }^{28}$ Los puntos centrales de esta políticas son: i) la creación de una oficina nacional de asilo; ii) una serie de leyes (una ley que desarrolla las cuestiones de asilo y refugio, una nueva ley de extranjería y una ley de lucha contra la trata de seres humanos); iii) la puesta en marcha de un proceso de regularización para extranjeros a partir el 1 de enero de 2014. A este procedimiento se presentaron 28.000 solicitudes, de las cuales 19.000 fueron favorables. Fueron denegados 9.000 solicitudes, todos varones. Los principales países fueron: Senegal, Siria, Nigeria, Costa de Marfil, Camerún, Guinea Conakry, RDC y Mali, iv) la elaboración de una estrategia de integración. 
rroquí y la Guardia Civil, hecho que ha sido largamente denunciado. A partir de 2005 se consolidó el endurecimiento y la militarización de esta frontera. Como señala Maleno (2010), este endurecimiento en el control provocó que en ciudades como Tánger las redes de trata sustituyeran a las redes de tráfico de personas. En febrero de 2014, en la frontera del Tarahal, en Ceuta, 15 personas murieron ahogadas por los golpes de las pelotas de goma, el humo y las balas de fogueo de la Guardia Civil. Las personas que llegaron a la playa no recibieron el debido derecho de socorro y fueron expulsadas automáticamente por la misma frontera, vulnerando así el derecho a solicitar asilo de los potenciales demandantes.

En los últimos años han sido constantes las operaciones de detención y expulsión. En la memoria de las comunidades del barrio de Bujalef están la muerte del senegalés Moussa Seck y la muerte del camerunés Cedric Béte en 2013, fruto de estas operaciones de detención. La comunidad camerunesa desfiló con el cadáver de Cédric exigiendo justicia desde Bujalef hacía el centro de la ciudad. El joven había muerto al caer de un cuarto piso en mitad de la persecución. A raíz de su muerte se creó en Tánger la Alianza Contra el Racismo y la Xenofobia, para exigir justicia por esta muerte. Pero fue imposible avanzar con un procedimiento judicial por las constantes trabas por parte de las autoridades.

Otras formas de violencia racista provocaron la muerte de otro compatriota senegalés, Charles Ndour que fue degollado. En Bujalef, tras meses de acoso, un día del mes de agosto de 2014 un grupo de personas armadas atacó a un grupo de africanos congregados en un apartamento. Se les acusaba de considerarlos responsables de la inseguridad en el barrio. "No somos racistas, pero no queremos negros", era una de las consignas en las manifestaciones de algunos vecinos del barrio. La ausencia total de autoridades en estos ataques constantes a las comunidades y la violencia como principal respuesta a los problemas de convivencia, culminan con una operación de desalojo narrada al principio de este texto.

La suma de todas estas actuaciones corrobora lo que algunos autores han denominado "la guerra a los migrantes" (Blanchard y Wender 2007) para denominar las políticas de represión y de disuasión de la inmigración en Marruecos.

\section{MOVILIDADES}

La externalización fronteriza en el Mediterráneo entra en crisis con la Primavera Árabe. A finales del 2011, la Unión Europea intenta responder a esta crisis a partir de una nueva formulación de la gestión de la movilidad que fortalece aún más los procesos de externalización. Nos referimos al Global Approach to Migration and Mobility que viene a ser el marco estratégico de la UE para articular los controles de sus fronteras. Las revueltas y revoluciones comenzadas en 2011, ponen, por un lado, en tela de juicio la citada Política Europea de Vecindad y desvelan el juego interesado de Europa en el control de la migración (Fargues et al. 2012). Por otro lado, fruto de los diferentes conflictos y guerras, principalmente en Libia, Siria y Yemen, se produce un aumento progresivo de refugiados, principalmente en los países del Sur y Este del Mediterráneo (Thiolet 2013) y en segundo lugar hacia Europa.

En este contexto, Tánger, no es más que una ciudad de tránsito clave entre los 
países de tránsito claves (Marconi, 2008), como Marruecos, Túnez o Libia. Tánger, inscrita en las dinámicas de la ciudad global (Sassen 1991), ya ha sido pensada como ciudad fronteriza paradigmática (Ribas-Mateos, 2005, 2015) en el Mediterráneo Occidental. La internacionalización del capital, la aceleración del éxodo rural, la articulación de políticas de control migratorio restrictivas o la tecnologización de las fronteras, se plasman en esta ciudad y su región. No sólo en Bujalef, en otros barrios de Tánger se agrupan personas con meses y años de espera. Mujeres, jóvenes, familias con bebés, pero principalmente varones solos, todos con un crisol de motivaciones y trayectorias. Es un lugar de descanso o la última oportunidad para los que se van quedando sin recursos y sin dinero en el trayecto hacia Europa.

Bujalef, en concreto la zona de Medina Al Irfane II, construida a mediados de los años 90 en pisos agrupados por bloques de cuatro alturas y con una ordenación coqueta, espaciosa y lineal, es escenario a la par de las violencias descritas y de la diversidad del hecho migratorio marroquí. Muchos de los propietarios de estos pisos son marroquíes llegados a la ciudad fruto del éxodo rural para trabajar en las zonas francas. Propietarios son también los marroquíes residentes en Europa que han comprado un apartamento en ese barrio aprovechando el dinero ahorrado o las condiciones óptimas de financiación que ofrecen los bancos marroquíes a los residentes en el extranjero.

En este barrio, las diferentes comunidades subsaharianas desplegaban sus formas de ocio, música, consumo, celebración, religiosidad, solidaridad, enfrentamiento y resistencia y buscaban formas de supervivencia en la espera. A través de la mendicidad, el dinero enviado por familiares y el trabajo en precario, iban sobreviviendo. En los últimos años habían surgido pequeños negocios, peluquerías o bares. Una nueva economía informal que convivía con la economía informal existente en el Norte del país. A través de las redes sociales se conectaba esta periferia de Tánger con las metrópolis europeas de Berlín, Estocolmo, Londres o París y del resto de África, como Dakar, Douala o Benin City.

En este contexto, la movilidad es un recurso y una forma de contestación a la lógica del control externalizado. El cruce del Estrecho de Gibraltar ya no se hacía solo con potentes lanchas y las pateras de madera hacía años que habían desaparecido. Las formas de cruzar pagando a un pasador estaban siendo sustituidas por la auto-organización, rebajando así muchísimo el precio del cruce, pero aumentando el riesgo de perder la vida en la travesía, porque ahora se cruzaba en botes de plástico, remos hechos a mano y neumáticos cruzados a modo de flotadores. Se cruzaba hacía las costas de Andalucía o hacia Ceuta. Pero estas formas de cruce tan precarias eran más arriesgadas, se ponía en riesgo la vida, el tiempo de reacción frente a algún problema en el cruce era mucho menor. $\mathrm{Y}$ es que el endurecimiento de los controles fronterizos siempre se salda con más muertes, es una ecuación que no falla en ninguna frontera del mundo.

\section{POLÍTICAS DE COMPASIÓN}

Volviendo al barrio de Bujalef y al grupo de personas desalojadas a principios del mes de julio de 2015, un grupo se encerró en la Catedral católica denunciando su situación y pidiendo ayuda. Desde el año 2013 estaba en marcha un proyecto finan- 
ciado por la Unión Europea de asistencia a migrantes procedentes de los países del Subsáhara y un dispositivo se había puesto en marcha (TAM, Tanger Acueil Migrants) liderado por la Delegación de Migraciones de la Diócesis de Tánger. El Arzobispo, desbordado por la situación y cuestionado en las redes sociales, daba explicaciones en su muro de Facebook a quienes lo criticaban por no actuar e implicarse más y más allá de la mera lógica del propio proyecto financiado por la UE. También, el propio alcalde de Tánger quiso hacer campaña para las próximas elecciones de septiembre y acudió a la Catedral católica prometiendo una intervención humanitaria de urgencia que nunca se produjo. La prensa lo fotografió junto al camión con cebollas, tomates y zumos que llevó hasta la puerta de la iglesia.

Del grupo de desalojados, otras 300 personas cogieron sus pocas pertenencias y se instalaron en un bosque cercano. Sin agua, sin comida, sin abrigo y sin las mínimas condiciones de salubridad. Una asociación internacional de asistencia médica les repartió bolsas de plástico para recoger la basura y adecentar el sitio y bidones de plástico para almacenar agua. Si había alguna urgencia médica les recomendaban ir al ambulatorio más cercano, pero allí no les atendían, sólo si asistían con alguna entidad que pagara los gastos. Otra asociación de lucha contra el sida se ofreció a hacerles el test gratuitamente allí en el mismo bosque. Una asociación local recibió dinero para repartir bolsas de comida pero no sabían cómo gestionar esta urgencia y repartir la comida. Otra entidad de derechos humanos regional organizó una caravana humanitaria para el grupo de personas que ya alcanzaban las 1.263 a finales del mes de julio. Desde Casablanca, otra entidad organizó otra caravana para celebrar el final del ramadán y entregar algunos donativos. Acciones desorganizadas, sin historia, confusas algunas y muy mediáticas otras. A pesar de que se actuaba a partir de una situación de emergencia provocada por el desalojo, lo cierto es que esta situación de vulnerabilidad venía ya durando casi unos 15 años. Ya en el año 2001, una entidad humanitaria realizó un primer diagnóstico sobre la situación de mujeres y niños en la medina de Tánger.

Las políticas de la compasión (Uehling 2014) son otra más forma sobre control de la movilidad y un elemento más en los procesos de externalización fronteriza. A través de políticas financiadas por la UE de cooperación internacional, se han ido implementando en Marruecos dispositivos "amables" de control de la población migrante (se les contabiliza, se les investiga, se les interpela, se les asiste). Este humanitarismo promueve una visión victimizadora de los "beneficiarios", a los que se les construye como sujetos pasivos y dignos de ser compadecidos. Estas lógicas del gobierno del humanitarismo (Fassin 2012) desplazan el debate de la vigencia de los Derechos Humanos desde su propia génesis jurídica hacia una perversa caridad que legitima formas de no-ciudadanía. Los migrantes en Europa y en las fronteras deslocalizadas están siendo sustentadores de estas políticas de la compasión. Toda una serie de intermediarios (cooperantes, médicos, trabajadores sociales, traductores) están siendo receptores de la mayor parte de los fondos dedicados a estas urgencias y que terminando cumpliendo la mayoría una misión de contención y cómputo.

Mientras tanto, los desalojados esperan a que se abra este verano otra vez la frontera al igual que el año pasado. Saben que Bujalef es sólo su penúltima frontera porque, realmente, la última frontera es Europa. 


\section{BIBLIOGRAFÍA CITADA}

Blanchard, Emmanuel y Anne-Sophie Wender. 2007. Guerre aux migrants. Le livre noir de Ceuta et Melilla. París: Editions Syllepse.

Fargues, Philippe and Fandrich, Christine. 2012. "Migration after the Arab Spring. Migration Policy Centre». Robert Schuman Centre for Advanced Studies. European University Institute. Disponible en: <http://www.migrationpolicycentre.eu/docs/MPC\%202012\%20EN\%2009.pdf >. Fecha de acceso: 1 de septiembre de 2015.

Fassin, Didier. 2012. Humanitarian Reason. A Moral History of the Present. Berkeley: University of California Press.

Jiménez-Álvarez, Mercedes. 2014. "Trasnacionalismo y régimen fronterizo: de lo jurídico, procedimental, institucional y conceptual.. En: Actas del XIII Congreso de Antropología de la Federación de Asociaciones de Antropología del Estado español. Disponible en: http://digital.publicacionsurv.cat/index.php/ purv/catalog/book/123. Fecha de acceso: 1 de septiembre 2015.

Uehling, Greta Lynn. 2014. "Las políticas de la compasión”, en Natalia Ribas-Mateos y Sofía Laiz, Sofía (eds.), Movilidades Adolescentes. Elementos teóricos emergentes en la ruta entre Marruecos y Europa: 129-159. Barcelona: Bellaterra.

Maleno, Helena. 2010. «Telón de fondo de las políticas migratorias”. Disponible en: Rompamos el silencio $<$ http://www.rompamoselsilencio.net/2010/?Telon-de-fondo-de-las-politicas $>$. Fecha de acceso: 01 sept. 2015.

Marconi, Giovanna. 2008. "Transit Cities in Transit Countries: Steering the Consequences of US and EU Closed Doors Policies", International Workshop Narratives of Migration Management and Cooperation with Countries Of Origin and Transit. Brighton: University of Sussex.

Thiollet, Hélène. 2013 "Migrations, exils et printemps arabes", en Frédéric Charillon y Alain Dieckhoff (dirs.), Afrique du Nord Moyen Orient 2013-2014. La double recomposition: 133-146. Paris: La Documentation Française.

Ribas-Mateos, Natalia. 2005. The Mediterranean in the Age of Globalization. Migration, Welfare and Borders. Piscataway, NJ: Transaction Publishers.

Ribas-Mateos, Natalia. 2015. A Sociological Study of Tangiers, Morocco. Nueva York: The Edwin Mellen Press.

Sassen, Saskia. 1991. The Global City: New York, London, Tokyo. Princeton: Pricenton University Press. 